\title{
Medical and surgical ward rounds in teaching hospitals of Kuwait University: students' perceptions
}

This article was published in the following Dove Press journal:

Advances in Medical Education and Practice

24 September 2013

Number of times this article has been viewed

\author{
Sara AIMutar' \\ Lulwa AlTourah' \\ Hussain Sadeq ${ }^{2}$ \\ Jumanah Karim² \\ Yousef Marwan ${ }^{3}$ \\ 'Department of Medicine, \\ 2Department of Pediatrics, Mubarak \\ Al-Kabeer Hospital, ${ }^{3}$ Department \\ of Orthopedic Surgery, Al-Razi \\ Orthopedic Hospital, Kuwait City, \\ Kuwait
}

Background: Teaching sessions for medical students during ward rounds are an essential component of bedside teaching, providing students with the opportunity to regard patients as actual people, and to observe their physical conditions directly, allowing a better understanding of illnesses to be developed. We aim to explore medical students' perceptions regarding medical and surgical ward rounds within the Faculty of Medicine at Kuwait University, and to evaluate whether this teaching activity is meeting the expectation of learners.

Methods: A pretested questionnaire was used to collect data from 141 medical students during the 2012-2013 academic year. They were asked to provide their current and expected ratings about competencies that were supposed to be gained during ward rounds, on a scale from 1 (lowest) to 5 (highest). Mean scores were calculated, and the Student $t$-test was used to compare results. $P<0.05$ was the cut-off level for significance.

Results: Only 17 students (12.1\%) declined to participate in the study. The students' current competency scores (for competencies taught within both disciplines - medical and surgical) were significantly lower than the scores indicating students' expectations $(P<0.001)$. The best-taught competency was bedside examination, in both medical (mean: 3.45) and surgical (mean: 3.05) ward rounds. However, medical ward rounds were better than surgical rounds in covering some competencies, especially the teaching of professional attitude and approach towards patients $(P<0.001)$.

Conclusion: Both medical and surgical ward rounds were deficient in meeting the students' expectations. Medical educators should utilize the available literature to improve the bedside teaching experience for their students.

Keywords: ward rounds, bedside teaching, undergraduate, medical students, medical education

\section{Introduction}

Bedside teaching is one of the main and essential components of medical education supported by learners and teachers. ${ }^{1-5}$ It is known as "teaching in the presence of patients", in the ward, outpatient clinic, emergency department, and operating room. Ward rounds, which represent a method for bedside teaching, provide medical students with opportunity to see patients as actual people, and to observe their physical conditions directly, allowing better understanding of illnesses to develop. ${ }^{5-7}$ Published research has proved that ward rounds can provide learners with opportunity to learn skills in history-taking, physical examination, diagnosis and treatment procedures, problem solving, professionalism, communication with patients and colleagues, decision making, ethical principles, teaching, management of patients, and teamwork. ${ }^{1,4,6-10}$
Correspondence: Yousef Marwan Department of Orthopedic Surgery, Al-Razi Orthopedic Hospital, PO Box 24923, Safat 13110, Kuwait Tel +96594060660 Fax +965 25330472 Email yousefmarwan@hotmail.com 
Moreover, patients in teaching hospitals consider it acceptable to teach medical students during ward round. ${ }^{11-14}$

Within the Faculty of Medicine at Kuwait University (FOMKU), students participate in ward rounds during the clinical phase of their curriculum (Years 5-7). In FOMKU teaching hospitals, ward round personnel usually comprise at least two attending doctors, at least one of whom is a consultant, and about four residents, two interns, and two medical students. The usual duration of the ward round is about two hours. Minor differences in duration and number of personnel exist between different specialties. During the round, attending doctors are responsible for teaching medical students, interns, and residents, as well as for case management of the patient. Interns and residents are not obliged to teach their juniors; A few doctors teach because they have personal interests in education. The undergraduate students are expected to gain knowledge in a variety of topics, and practice a number of skills. Relevant learning outcomes are assessed continuously during specific clinical rotations (ie, in-course assessments), and again, later, in the form of written tests (eg, multiple choice) and clinical examinations (eg, objective structured clinical examination).

Previous studies have revealed that medical students in Kuwait lack clinical skills. However, there is no evidence available to show whether this deficiency is due to inadequate ward round training. ${ }^{15,16}$ In this study, we aim to provide an assessment of medical and surgical ward round sessions in FOMKU teaching hospitals, based on the opinions of medical students. This will help in identifying weaknesses of the rounds, thus enabling medical educators to improve this teaching modality.

\section{Methods}

\section{Data collection instrument}

We developed a self-administered, English-language questionnaire, which consisted of 34 questions, grouped in two main sections. Section 1 has a set of four questions about the background characteristics of the participants, including age, gender, year of study in medical school, and Grade Point Average (GPA). Section 2, which is adapted with permission from a previously-published study, relates to ward rounds. ${ }^{10}$ In this section, students were asked to provide current and expected self-ratings, on a scale from 1 (lowest) to 5 (highest), of competencies gained during medical and surgical ward rounds. The questionnaire was pretested on ten randomly-selected students, to ensure clarity of the questions.

\section{Study design and participants}

This cross-sectional study was conducted during February 2013; data were collected from the 10th to the 28th of this month. Our study sample consisted of students at FOMKU who had each completed at least 10 weeks of rotation on surgical and medical ward rounds. Thus, only students enrolled in the final two years of medical school (Years 6-7) were eligible to participate. We were able to contact 68 (of 91) and 73 (of 95) sixth- and seventh-year medical students, respectively. Only 17 students (12.1\%) declined to participate in the study, without citing any reasons.

Written, informed consent was obtained from each participant, after explanation of the study's objectives. All participants were assured of the confidentiality of the information to be collected, and that they were free to decline to participate in the study. The study protocol and data collection instrument were approved by the research ethics committee of Kuwait University.

\section{Statistical analysis}

We analyzed data using SPSS Version 17.0 statistical software (IBM Corp, Armonk, NY, USA). We used $P<0.05$ as the cut-off for significance. We computed descriptive analysis of all variables. We used the Student's $t$-test to compare mean scores. A comparison was made between current and expected scores for competencies within each specialty.

\section{Results}

Table 1 shows background information about the participating students. Half of them $(n=62,50.0 \%)$ were older than 23 years old. Male students comprised about two-thirds ( $\mathrm{n}=82,66.1 \%)$. Most students were registered in their seventh year of study $(n=69,55.6 \%)$, and had a GPA between 2.51-2.99 $(\mathrm{n}=62,50.0 \%)$.

The means of current and expected scores of competencies covered during medical and surgical ward rounds are shown in Tables 2 and 3, respectively. The highest current competency score (indicating the competency best covered), for all the competencies covered in medical ward rounds, was for bedside examination (3.48), while the lowest current competency score (indicating the competency covered the least effectively) was for managerial skills (1.78). Students reported that all competencies were important, and were expected to be covered more effectively during medical ward rounds (the range of expected competency scores, for all competencies, was 4.30-4.76), with bedside examination rated the most important to be acquired during medical ward rounds. Similar findings were noted for surgical ward rounds, in which the 
Table I Background information for medical students at Kuwait University during academic year 2012-2013

\begin{tabular}{lll}
\hline Characteristic & $\mathbf{N}$ & $\%$ \\
\hline Total & 124 & 100.0 \\
Age (years) & & \\
$\quad \leq 23$ & 62 & 50.0 \\
$>23$ & 62 & 50.0 \\
$\quad$ Mean \pm SD & $23.56 \pm 0.839$ & \\
$\quad$ Range & $22-26$ & \\
Gender & & 66.1 \\
$\quad$ Male & 82 & 33.9 \\
Female & 42 & \\
Year of study & & 44.4 \\
$\quad$ Year 6 & 55 & 55.6 \\
$\quad$ Year 7 & 69 & \\
GPA (out of 4.00) & & 35.5 \\
$\quad 2.5$ & 44 & 50.0 \\
$2.5 I-2.99$ & 62 & 14.5 \\
$\quad \geq 3.0$ & 18 & \\
\hline
\end{tabular}

Abbreviations: *SD, standard deviation; GPA, Grade Point Average.

highest current competency score was for bedside examination (3.05), and the lowest was for managerial skills (1.91). All competencies were expected to be covered more effectively during these rounds (the range of expected scores, for all competencies, was 4.33-4.64), with bedside examination

Table 2 Medical students' perspectives regarding medical ward rounds in covering learning competencies at Kuwait University during academic year 2012-2013

\begin{tabular}{|c|c|c|c|}
\hline Competency & $\begin{array}{l}\text { Current } \\
\text { score* } \\
\text { (Mean } \pm \text { SD) }\end{array}$ & $\begin{array}{l}\text { Expected } \\
\text { score* } \\
\text { (Mean } \pm \text { SD) }\end{array}$ & $P$-value** \\
\hline $\begin{array}{l}\text { Conveying medical } \\
\text { knowledge }\end{array}$ & $3.02 \pm 1.028$ & $4.40 \pm 0.764$ & $<0.001$ \\
\hline Teaching clinical skills & $2.16 \pm 1.114$ & $4.45 \pm 0.905$ & $<0.001$ \\
\hline Professional attitude & $2.97 \pm 1.189$ & $4.66 \pm 0.673$ & $<0.001$ \\
\hline Communication skills & $2.78 \pm 1.240$ & $4.60 \pm 0.685$ & $<0.001$ \\
\hline $\begin{array}{l}\text { Clinical problem } \\
\text { solving ability }\end{array}$ & $3.12 \pm 1.079$ & $4.60 \pm 0.719$ & $<0.001$ \\
\hline Presentation skills & $3.00 \pm 1.243$ & $4.49 \pm 0.770$ & $<0.001$ \\
\hline $\begin{array}{l}\text { Approach towards } \\
\text { patients }\end{array}$ & $3.17 \pm 1.131$ & $4.66 \pm 0.685$ & $<0.001$ \\
\hline $\begin{array}{l}\text { Management of } \\
\text { patients }\end{array}$ & $3.10 \pm 1.039$ & $4.56 \pm 0.735$ & $<0.001$ \\
\hline $\begin{array}{l}\text { Ability to discuss } \\
\text { problems logically }\end{array}$ & $3.17 \pm 1.080$ & $4.35 \pm 0.876$ & $<0.001$ \\
\hline Medical ethics & $2.43 \pm 1.191$ & $4.32 \pm 0.942$ & $<0.001$ \\
\hline Counseling & $2.43 \pm 1.177$ & $4.56 \pm 0.778$ & $<0.001$ \\
\hline Bedside examination & $3.48 \pm 1.040$ & $4.76 \pm 0.655$ & $<0.001$ \\
\hline Managerial skills & $1.78 \pm 1.101$ & $4.36 \pm 0.931$ & $<0.001$ \\
\hline Leadership skills & $2.04 \pm 1.165$ & $4.30 \pm 0.971$ & $<0.001$ \\
\hline Teamwork & $2.59 \pm 1.331$ & $4.42 \pm 0.947$ & $<0.001$ \\
\hline
\end{tabular}

Notes: *A score of $\mathrm{I}$ is lowest; 5 is highest; **Student's $t$-test for independent samples.

Abbreviation: SD, standard deviation.
Table 3 Medical students' perspectives regarding surgical ward rounds in covering learning competencies at Kuwait University during academic year 2012-2013

\begin{tabular}{|c|c|c|c|}
\hline Competency & $\begin{array}{l}\text { Current } \\
\text { score* } \\
\text { (Mean } \pm \text { SD) }\end{array}$ & $\begin{array}{l}\text { Expected } \\
\text { score* } \\
(\text { Mean } \pm \text { SD) }\end{array}$ & $P$-value** \\
\hline $\begin{array}{l}\text { Conveying medical } \\
\text { knowledge }\end{array}$ & $2.62 \pm 1.109$ & $4.44 \pm 0.779$ & $<0.001$ \\
\hline Teaching clinical skills & $2.18 \pm 1.127$ & $4.49 \pm 0.821$ & $<0.001$ \\
\hline Professional attitude & $2.34 \pm 1.147$ & $4.59 \pm 0.744$ & $<0.001$ \\
\hline Communication skills & $2.43 \pm 1.191$ & $4.56 \pm 0.789$ & $<0.001$ \\
\hline $\begin{array}{l}\text { Clinical problem } \\
\text { solving ability }\end{array}$ & $2.65 \pm 1.075$ & $4.54 \pm 0.726$ & $<0.001$ \\
\hline Presentation skills & $2.60 \pm 1.140$ & $4.38 \pm 0.86 I$ & $<0.001$ \\
\hline $\begin{array}{l}\text { Approach towards } \\
\text { patients }\end{array}$ & $2.54 \pm 1.062$ & $4.55 \pm 0.790$ & $<0.001$ \\
\hline $\begin{array}{l}\text { Management of } \\
\text { patients }\end{array}$ & $2.91 \pm 1.141$ & $4.59 \pm 0.755$ & $<0.001$ \\
\hline $\begin{array}{l}\text { Ability to discuss } \\
\text { problems logically }\end{array}$ & $2.86 \pm 1.107$ & $4.51 \pm 0.801$ & $<0.001$ \\
\hline Medical ethics & $2.17 \pm 1.080$ & $4.37 \pm 0.932$ & $<0.001$ \\
\hline Counseling & $2.44 \pm 1.135$ & $4.58 \pm 0.755$ & $<0.001$ \\
\hline Bedside examination & $3.05 \pm 1.168$ & $4.64 \pm 0.714$ & $<0.001$ \\
\hline Managerial skills & $1.91 \pm 1.097$ & $4.35 \pm 0.955$ & $<0.001$ \\
\hline Leadership skills & $2.15 \pm 1.237$ & $4.33 \pm 0.943$ & $<0.001$ \\
\hline Teamwork & $2.49 \pm 1.29 \mid$ & $4.47 \pm 0.869$ & $<0.001$ \\
\hline
\end{tabular}

Notes: *A score of $I$ is lowest; 5 is highest; **Student's $t$-test for independent samples.

Abbreviation: SD, standard deviation.

Table 4 Comparison between the current status of medical and surgical ward rounds in covering learning competencies based on the students' opinion at Kuwait University during academic year 2012-2013

\begin{tabular}{llll}
\hline Competency & $\begin{array}{l}\text { Medical } \\
\text { round score* } \\
\text { (Mean } \pm \text { SD) }\end{array}$ & $\begin{array}{l}\text { Surgical } \\
\text { round score* } \\
\text { (Mean } \pm \text { SD) }\end{array}$ & P-value** \\
\hline $\begin{array}{l}\text { Conveying medical } \\
\text { knowledge }\end{array}$ & $3.02 \pm 1.028$ & $2.62 \pm 1.109$ & 0.004 \\
Teaching clinical skills & $2.16 \pm 1.114$ & $2.18 \pm 1.127$ & 0.910 \\
Professional attitude & $2.97 \pm 1.189$ & $2.34 \pm 1.147$ & $<0.001$ \\
Communication skills & $2.78 \pm 1.240$ & $2.43 \pm 1.191$ & 0.022 \\
Clinical problem & $3.12 \pm 1.079$ & $2.65 \pm 1.075$ & 0.001 \\
solving ability & & & \\
Presentation skills & $3.00 \pm 1.243$ & $2.60 \pm 1.140$ & 0.008 \\
Approach towards & $3.17 \pm 1.131$ & $2.54 \pm 1.062$ & $<0.001$ \\
patients & $3.10 \pm 1.039$ & $2.91 \pm 1.141$ & 0.182 \\
Management of patients & $3.17 \pm 1.080$ & $2.86 \pm 1.107$ & 0.028 \\
Ability to discuss & & & \\
problems logically & $2.43 \pm 1.191$ & $2.17 \pm 1.080$ & 0.075 \\
Medical ethics & $2.43 \pm 1.177$ & $2.44 \pm 1.135$ & 0.956 \\
Counseling & $3.48 \pm 1.040$ & $3.05 \pm 1.168$ & 0.003 \\
Bedside examination & $1.78 \pm 1.101$ & $1.91 \pm 1.097$ & 0.356 \\
Managerial skills & $2.04 \pm 1.165$ & $2.15 \pm 1.237$ & 0.460 \\
Leadership skills & $2.59 \pm 1.331$ & $2.49 \pm 1.291$ & 0.562 \\
\hline Teamwork & &
\end{tabular}

Notes: *A score of $\mathrm{I}$ is lowest; 5 is highest; **Student's $t$-test for independent samples.

Abbreviation: SD, standard deviation. 
Table $\mathbf{5}$ Comparison between the expected status of medical and surgical ward rounds in covering learning competencies based on the students' opinion at Kuwait University during academic year $2012-2013$

\begin{tabular}{|c|c|c|c|}
\hline Competency & $\begin{array}{l}\text { Medical } \\
\text { round score* } \\
(\text { Mean } \pm \text { SD) }\end{array}$ & $\begin{array}{l}\text { Surgical } \\
\text { round score* } \\
\text { (Mean } \pm \text { SD) }\end{array}$ & $P$-value** \\
\hline $\begin{array}{l}\text { Conveying medical } \\
\text { knowledge }\end{array}$ & $4.40 \pm 0.764$ & $4.44 \pm 0.779$ & $0.68 I$ \\
\hline Teaching clinical skills & $4.45 \pm 0.905$ & $4.49 \pm 0.821$ & 0.714 \\
\hline Professional attitude & $4.59 \pm 0.744$ & $4.59 \pm 0.744$ & 0.421 \\
\hline Communication skills & $4.60 \pm 0.685$ & $4.56 \pm 0.789$ & 0.606 \\
\hline $\begin{array}{l}\text { Clinical problem } \\
\text { solving ability }\end{array}$ & $4.60 \pm 0.719$ & $4.54 \pm 0.726$ & 0.483 \\
\hline Presentation skills & $4.49 \pm 0.770$ & $4.38 \pm 0.86 \mid$ & 0.278 \\
\hline $\begin{array}{l}\text { Approach towards } \\
\text { patients }\end{array}$ & $4.66 \pm 0.685$ & $4.55 \pm 0.790$ & 0.230 \\
\hline Management of patients & $4.56 \pm 0.735$ & $4.59 \pm 0.755$ & 0.798 \\
\hline $\begin{array}{l}\text { Ability to discuss } \\
\text { problems logically }\end{array}$ & $4.35 \pm 0.876$ & $4.5 \mathrm{I} \pm 0.80 \mathrm{I}$ & 0.152 \\
\hline Medical ethics & $4.32 \pm 0.942$ & $4.37 \pm 0.932$ & 0.685 \\
\hline Counseling & $4.56 \pm 0.778$ & $4.58 \pm 0.755$ & 0.869 \\
\hline Bedside examination & $4.76 \pm 0.655$ & $4.64 \pm 0.714$ & 0.166 \\
\hline Managerial skills & $4.36 \pm 0.931$ & $4.35 \pm 0.955$ & 0.893 \\
\hline Leadership skills & $4.30 \pm 0.971$ & $4.33 \pm 0.943$ & 0.791 \\
\hline Teamwork & $4.42 \pm 0.947$ & $4.47 \pm 0.869$ & 0.675 \\
\hline
\end{tabular}

Notes: *A score of $\mathrm{I}$ is lowest; 5 is highest; **Student's $t$-test for independent samples.

Abbreviation: SD, standard deviation.

rated the highest. Comparison between current and expected competency scores, for those competencies covered by both rounds, showed that all current scores were significantly lower than expected scores $(P<0.001)$.

Comparisons between medical and surgical ward rounds are shown in Tables 4 and 5. Eight competencies received significantly higher current competency scores when covered during medical rounds than when covered during surgical rounds $(P<0.05)$. The greatest differences were noted for the competencies "professional attitude" and "approach towards patients" $(P<0.001)$. No significant difference was observed between expected competency scores between medical and surgical rounds.

\section{Discussion and conclusions}

This study demonstrates that bedside teaching sessions during medical and surgical ward rounds in FOMKU teaching hospitals did not meet students' expectations. This implies that ward rounds are underutilized as a way of teaching medical students, despite them being the most frequently undertaken bedside activity. Similar results have been noted in previous studies, where learners felt that ward round teaching sessions did not meet their expectations. ${ }^{10,17-20}$ Our students also reported that the medical ward rounds are better than the surgical ones. This might be because surgeons spend a significant proportion of their working hours in the operation room, leaving less time for teaching in the wards. These findings could explain students' lack of proper bedside clinical skills in Kuwait and other countries. ${ }^{15,16,21-24}$ It is necessary to expend sufficient time and effort to make improvements to this fundamental teaching activity.

To start improving teaching activities during ward rounds, educators need to understand potential barriers. Many authors have reported on barriers to bedside teaching, using different classification schemes. ${ }^{9,25-27}$ Ramani et al classified barriers against bedside teaching into: (1) teacher-related barriers, such as lack of experience or motivation, and difficulty in engaging all team members; (2) teaching climate-related barriers, such as time constraints, and lack of reward for teaching; (3) system-related barriers, such as interruptions by patients' visitors, and short patient stays; (4) patient-related barriers, such as patient absence due to medical procedure, and uncooperative or angry patients, and (5) miscellaneous barriers, such as there being a large crowd in a small room, and learner fatigue. ${ }^{25}$ By contrast, Williams et al divided barriers faced by clinical teachers into three classes: (1) personal barriers, such as inadequate bedside teaching skills, and low initiative for teaching; (2) interpersonal barriers, such as lack of patient cooperation, and learner or patient fear of embarrassment; and (3) environmental barriers, such as interruptions during rounds, and competing responsibilities. ${ }^{26}$ In order to overcome these barriers, and provide a more educational ward round, multiple models and methods have been proposed for medical educators. ${ }^{4,27-30}$ All of these methods share a similar general concept. They suggest that clinical educators should begin planning the session before the start of the round, and set teaching objectives, with knowledge of the learners and patients. During the rounds, the teacher should have the proper skills and techniques for communicating with different groups of learners and patients, should ensure their comfort, and should consider how to formulate and ask questions, how to deal with limited time, how to manage the team, how to improve the teaching style, and how to provide a favorable atmosphere for learning. After the rounds, feedback should be delivered appropriately by the teacher to the learners.

Although this study has revealed the weaknesses of teaching on medical and surgical ward rounds in Kuwait, it is limited by a few issues. Our students had different experiences of ward rounds, since not all of them were at the same teaching hospital. This provided only general 
ratings for teaching activities during ward rounds, not specific to one hospital. Moreover, we did not invite students to participate in the study during, or immediately after, completing, their rotation. This could have resulted in recall bias. In addition, this study provided a unilateral point of view (ie, only the opinions of the learners were assessed).

Both medical and surgical ward rounds at FOMKU are deficient in meeting students' expectations of the bedside learning experience. Medical educators at FOMKU should utilize the available literature in order to improve the bedside teaching experience of their students, and to help them to continue evaluating their teaching activities, in order to ensure proper medical education of undergraduates.

\section{Acknowledgment}

We would like to thank Dr Muhammad Tariq for allowing us to adapt and use part of the questionnaire used in his study. ${ }^{10}$

\section{Disclosure}

The authors report no conflicts of interest in this work.

\section{References}

1. Doshi M, Brown N. Whys and hows of patient-based teaching. Adv Psychiatr Treat. 2005;11:223-231.

2. Fitzgerald FT. Bedside teaching. West J Med. 1993;158(4):418-420.

3. LaCombe MA. On bedside teaching. Ann Intern Med. 1997;126(3): 217-220

4. Janicik RW, Fletcher KE. Teaching at the bedside: a new model. Med Teach. 2003;25(2):127-130.

5. Aldeen AZ, Gisondi MA. Bedside teaching in the emergency department. Acad Emerg Med. 2006;13(8):860-866.

6. Ahmed M El-Bagir K. What is happening to bedside clinical teaching? Med Educ. 2002;36(12):1185-1188.

7. Seo M, Tamura K, Morioka E, Shijo H. Impact of medical round on patients' and residents' perceptions at a university hospital in Japan. Med Educ. 2000;34(5):409-411.

8. Lehmann LS, Brancati FL, Chen MC, Roter D, Dobs AS. The effect of bedside case presentations on patients' perceptions of their medical care. N Engl J Med. 1997;336(16):1150-1155.

9. Ahmed AM. Bedside teaching at the Cinderella status. Options for promotion. Saudi Med J. 2010;31:739-746.

10. Tariq M, Motiwala A, Ali SU, Riaz M, Awan S, Akhter J. The learners' perspective on internal medicine ward rounds: a cross-sectional study. BMC Med Educ. 2010;10:53.

11. Marwan Y, Al-Saddique M, Hassan A, Karim J, Al-Saleh M. Are medical students accepted by patients in teaching hospitals? Med Educ Online. 2012;17:17172.
12. Chipp E, Stoneley S, Cooper K. Clinical placements for medical students: factors affecting patients' involvement in medical education. Med Teach. 2004;26(2):114-119.

13. Fletcher KE, Rankey DS, Stern DT. Bedside interactions from the other side of the bedrail. J Gen Intern Med. 2005;20(1):58-61.

14. Passaperuma K, Higgins J, Power S, Taylor T. Do patients' comfort levels and attitudes regarding medical student involvement vary across specialties? Med Teach. 2008;30(1):48-54.

15. Karim JA, Marwan YA, Dawas AM, Akhtar S. Self-confidence of medical students in performing clinical skills acquired during their surgical rotation: Assessing clinical skills education in Kuwait. Saudi Med J. 2012;33(12):1310-1316.

16. Karim J, Al-Saraji M, Al-Mousawi F, et al. Knowledge and self-reported practice of universal precautions among Kuwait University medical students in their clinical years. Med Princ Pract. 2012;21(4):328-333.

17. Qureshi NS, Swamy NN. Postgraduate trainees' assessment of the educational value of ward rounds in obstetrics and gynaecology. $J$ Obstet Gynaecol. 2008;28(7):671-675.

18. Nair BR, Coughlan JL, Hensley MJ. Student and patient perspectives on bedside teaching. Med Educ. 1997;31(5):341-346.

19. Birtwistle L, Houghton JM, Rostill H. A review of a surgical ward round in a large paediatric hospital: does it achieve its aims? Med Educ. 2000;34(5):398-403.

20. Williams KN, Ramani S, Fraser B, Orlander JD. Improving bedside teaching: findings from a focus group study of learners. Acad Med. 2008;83(3):257-264.

21. Nikendei C, Kraus B, Schrauth M, Briem S, Junger J. Ward rounds: how prepared are future doctors? Med Teach. 2008;30(1):88-91.

22. Nikendei C, Kraus B, Lauber H, et al. An innovative model for teaching complex clinical procedures: integration of standardised patients into ward round training for final year students. Med Teach. 2007;29(2-3): 246-252.

23. Fischer T, Chenot JF, Simmenroth-Nayda A, Heinemann S, Kochen MM, Himmel W. Learning core clinical skills - a survey at 3 time points during medical education. Med Teach. 2007;29(4):397-399.

24. Wu EH, Fagan MJ, Reinert SE, Diaz JA. Self-confidence in and perceived utility of the physical examination: a comparison of medical students, residents, and faculty internists. J Gen Intern Med. 2007;22(12): 1725-1730.

25. Ramani S, Orlander JD, Strunin L, Barber TW. Whither bedside teaching? A focus-group study of clinical teachers. Acad Med. 2003;78(4):384-390.

26. Williams KN, Ramani S, Fraser B, Orlander JD. Improving bedside teaching: findings from a focus group study of learners. Acad Med. 2008;83(3):257-264.

27. Ramani S, Leinster S. AMEE Guide no 34: Teaching in the clinical environment. Med Teach. 2008;30(4):347-364.

28. Roy B, Castiglioni A, Kraemer RR, et al. Using cognitive mapping to define key domains for successful attending rounds. J Gen Intern Med. 2012;27(11):1492-1498.

29. Certain LK, Guarino AJ, Greenwald JL. Effective multilevel teaching techniques on attending rounds: a pilot survey and systematic review of the literature. Med Teach. 2011;33(12):e644-e650.

30. Stickrath C, Aagaard E, Anderson M. MiPLAN: a learner-centered model for bedside teaching in today's academic medical centers. Acad Med. 2013;88(3):322-327.
Advances in Medical Education and Practice

\section{Publish your work in this journal}

Advances in Medical Education and Practice is an international, peerreviewed, open access journal that aims to present and publish research on Medical Education covering medical, dental, nursing and allied health care professional education. The journal covers undergraduate education, postgraduate training and continuing medical education

\section{Dovepress}

including emerging trends and innovative models linking education, research, and health care services. The manuscript management system is completely online and includes a very quick and fair peer-review system. Visit http://www.dovepress.com/testimonials.php to read real quotes from published authors. 